\title{
Perinatal Effects of Metformin use in Gestational Diabetes
}

\author{
${ }^{1}$ General Physician, Universidad Técnica de Ambato, Ecuador \\ ${ }^{2}$ General Physician, Universidad Militar Nueva Granada, Bogotá, Colombia \\ ${ }^{3}$ General Physician, Universidad del Sinú de Montería, Colombia \\ ${ }^{4}$ General Physician, Universidad del Sinú, Colombia \\ ${ }^{5}$ General Physician, Universidad Industrial de Santander, Colombia \\ ${ }^{6}$ General Physician, Universidad del Sinú, Colombia \\ ${ }^{7}$ General Physician, Universidad del Sinú, Cartagena, Colombia \\ ${ }^{8}$ General Physician, Universidad del Norte, Colombia
}

Karen Mireya Topa Pila ${ }^{1 *}$, Carlos Acosta Reyes ${ }^{2}$, Miguel Arturo Llanos Guzmán ${ }^{3}$, Helvey Ramón Zetién Arteaga ${ }^{4}$, Lizeth Yurany Gómez Flórez $^{5}$, Daniel Jesús Villanueva Navarro ${ }^{6}$, Paula Andrea Navarro Guerrero ${ }^{7}$, Katia García Pertuz ${ }^{8}$

*Corresponding Author: Karen Mireya Topa Pila, General Physician, Universidad Técnica de Ambato, Ecuador.

Received date: November 18, 2021; Accepted date: December 03, 2021; Published date: December 08, 2021

Citation: Topa Pila KM, Carlos A. Reyes., Llanos Guzmán MA., Zetién Arteaga HR., Gómez Flórez LY, et all (2021). Perinatal Effects of Metformin use in Gestational Diabetes. J. Women Health Care and Issues. 4(7); DOI:10.31579/2642-9756/094

Copyright: () 2021 Karen Mireya Topa Pila, This is an open access article distributed under the Creative Commons Attribution License, which permits unrestricted use, distribution, and reproduction in any medium, provided the original work is properly cited.

\section{Abstract}

Background: GD is a condition in which a woman develops glucose intolerance at any time during pregnancy and may or may not resolve at the end of pregnancy. Metformin, from the group of biguanides, is considered an alternative management of gestational diabetes, included in the list of essential medicines by the OMS.

Methodology: A narrative review was carried out through various databases from March 2018 to September 2021; the search and selection of articles was carried out in journals indexed in English and Spanish. The following keywords were used: metformin, macrosomia, gestational diabetes.

Results: The present review offers pathophysiological measures, complications, pharmacological therapy, for a better approach in perinatals in patients with gestational diabetes.

Conclusion: With the results observed, it should be noted that metformin is viable for the management of patients with gestational diabetes.

Key words: metformin; macrosomia; gestational diabetes

\section{Introduction:}

Gestational diabetes is a decrease in tolerance to carbohydrates that occurs during pregnancy, is associated with adverse results for both the mother and the fetus if it is not controlled, it usually occurs in the second trimester of pregnancy, Since in this they develop an increase in peripheral resistance to insulin at the post-receptor level mediated by high plasma levels of diabetogenic hormones, however, it reaches its peak at week 32, this would have risky maternal-fetal consequences. (1)

When normal glucose figures are not obtained with treatment based on diet and exercise, it is necessary to implement pharmacological treatment, with oral hypoglycemic agents, taking into account that metabolic control is essential to avoid perinatal complications for the mother, such as hypertension gestational disease, pre-eclampsia, development of postpartum type II DM, polyhydramnios and premature delivery, among others. In the case of the fetus, complications such as macrosomia, hypoglycemia, hyperbilirubinemia, hypocalcemia, among other complications, can be generated. It should be noted that several studies affirm that the use of metformin for glycemic control is safe and effective, especially for lower strata, since thanks to its low commercial cost it is accessible and there is better adherence to its route of administration, although its Long-term effects. [1,2]

Treatment methods may vary depending on the characteristics of each patient, including insulin and metformin being the most favorable options for the treatment of gestational diabetes.

The objective of this article is to identify the possible perinatal effects that may occur due to the consumption of metformin in gestational diabetes. 


\section{Materials and Methods}

A narrative review was carried out, in which the databases of the Journal of Medical-Surgical Specialties, Elsevier, and ScienceDirect, among others, were searched. The collection and selection of articles was carried out in journals indexed in English from the years 2018 to 2021. As keywords, the terms were used in the databases according to the DeCS and MeSH methodology; metformin, macrosomia, diabetes. In this review, 716 original and review publications related to the subject studied were identified, of which 15 articles met the specified inclusion requirements, such as articles that were in a range not less than the year 2018, which were articles of full text and to report on the perinatal effects of the use of metformin in gestational diabetes. As exclusion criteria, it was taken into account that the articles did not have sufficient information and that they did not present the full text at the time of their review.

\section{Discussion and Results}

\section{Pathophysiology of gestational diabetes}

It should be noted that for the approach to this pathology it is important to remember that during the first 6 of normal pregnancy, estrogens and progesterone stimulate hyperplasia of the B cells of the pancreas in addition to generating increases in insulin secretion in order to increase the glycogen stores for subsequent fetal growth. During this stage, insulin resistance remains stable; As gestation progresses, insulin sensitivity decreases to $50 \%$ in the third trimester. During this process, the production of placental lactogen and growth hormones participates, releasing cytokines by adipocytes, which increases the concentration of free acids, in addition to a decrease in the plasma concentration of adiponectin, All of the above results in a peripheral decrease in glucose between 40 and $60 \%$. [2]

Because glucose is transported to the fetus by means of facilitated diffusion, physiological insulin resistance favors the uptake of fetal glucose in such a way that in a normal pregnancy, glycemia remains within normal ranges by an increase between 200-250\% insulin. [2.1]
Following the topic, the regulation of fetal glucose metabolism requires that the maternal glucose concentration, the placental transfer of glucose and the adequate production of fetal insulin be established to be stable, in addition to its entry into peripheral fetal tissues. [2.2]

Women diagnosed with gestational diabetes show an increase in fasting and postprandial glucose, which generates greater fetal glucose transfer and stimulates fetal insulin secretion, during the state of fetal hyperinsulinemia promotes anabolism which causes large fetuses for gestational age and increased risk of organic damage. [23]

\section{Complications of gestational diabetes.}

As we well know, gestational diabetes does not present symptoms, for this reason it is important to carry out an early diagnosis in a timely manner, since if it is not treated in time, it presents maternal-fetal complications. [3]

Among the maternal risks that have been documented are; increased risk of hypertensive diseases which is related to fluctuations in glucose levels since these have a greater impact on the endothelial function of sustained hyperglycemia, in these patients there is a greater need for induction of labor and cesarean section In addition to the fact that there is a greater risk of uterine rupture, shoulder dystocia, and perinatal relationships due to the presence of large-for-gestational age neonates, it has also been documented that there is a greater risk of preterm delivery and the presence of metabolic dysfunction with a cumulative incidence of DM2 that it ranges from 10 to $20 \%$ within the next 10 years. [3.1]

Now, speaking of the children of mothers with gestational diabetes, adverse neonatal complications include growth disorders (macrosomia), neonatal hypoglycemia, respiratory distress syndrome, perinatal asphyxia, fractures, brachial plexus palsy, neonatal hyperbilirubinemia, hypertrophic heart disease, polycythemia, hypocalcemia, hypomagnesemia, and higher rate of admission to the neonatal intensive care unit (NICU), there is evidence that fetal hyperinsulinemia produces hypokalemia, which can cause fetal arrhythmias and ultimately death (Figure 1). [4]

\section{Fetal}

\section{consequences}

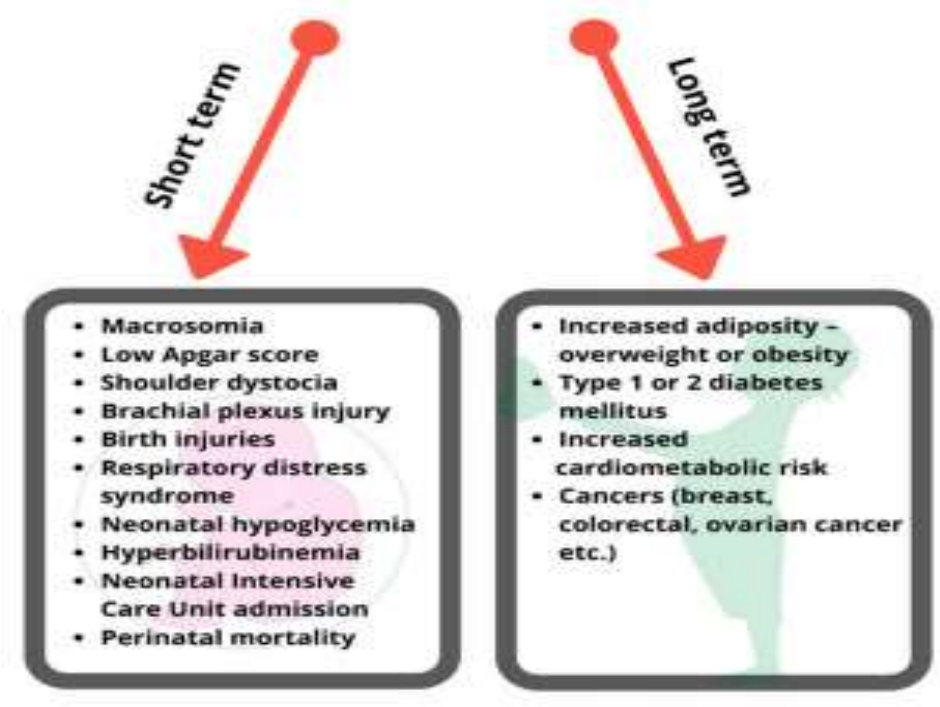

Figure 1: Fetal complications of gestational diabetes 
Taken from Cozma MA, Găman MA, Dobrică EC, Boroghină SC, Iancu MA, Crețoiu SM, Simionescu AA. A look at the size of the fetal liver: is it related to the course of gestational diabetes? International Journal of Molecular Sciences. 2021; 22 (15): 7866.

https://doi.org/10.3390/ijms22157866

Preterm birth is the leading cause of neonatal death in pregnant diabetics. Fetal hyperglycemia and hyperinsulinemia interfere with surfactant synthesis by type 2 pneumocytes and lung maturation, conferring an increased risk of respiratory distress and neonatal death. [5]

It is important to highlight that intrauterine conditions in which tissues and organs develop have greater adiposity, fatty tissue and more skin folds, in addition to the increased risk of presenting long-term metabolic complications such as being overweight among others. [6]

\section{Metformin}

Metformin, belonging to the group of biguanides, is the first choice in patients with diabetes, with preserved renal function after recommending initiating a change in lifestyle at the time of GD diagnosis, as agreed by the European Association for the Study of Diabetes (EASD), the
American Diabetes Association (ADA) and the main clinical practice guidelines. Even when these patients initiate insulinization, metformin treatment should continue.

Pharmacological treatment is favored by its low cost, easy administration, and acceptability among patients, making it an acceptable alternative. Highlighting that, being a hypoglycemic agent, metformin is considered a potential substitute for insulin in the management of gestational diabetes. In controlled studies involving women with GD, the use of metformin, either in conjunction with insulin or alone, was not associated with an increase in perinatal complications compared to insulin alone. Metformin began to be used to treat diabetes in humans in 1995, which was approved for use in the United States, while its first report in pregnant women was registered in 1970. [7]

Among the effects of metformin is the suppression of hepatic gluconeogenesis, which could be beneficial for the preservation of the function of pancreatic B cells, which increases the suppression of insulin, stimulates the uptake of glucose in peripheral tissue and reduction of glucose absorption in the gastrointestinal tract, thus increasing insulin sensitivity without stimulating its release in such a way that it does not generate hypoglycemia (Figure 2). [8]

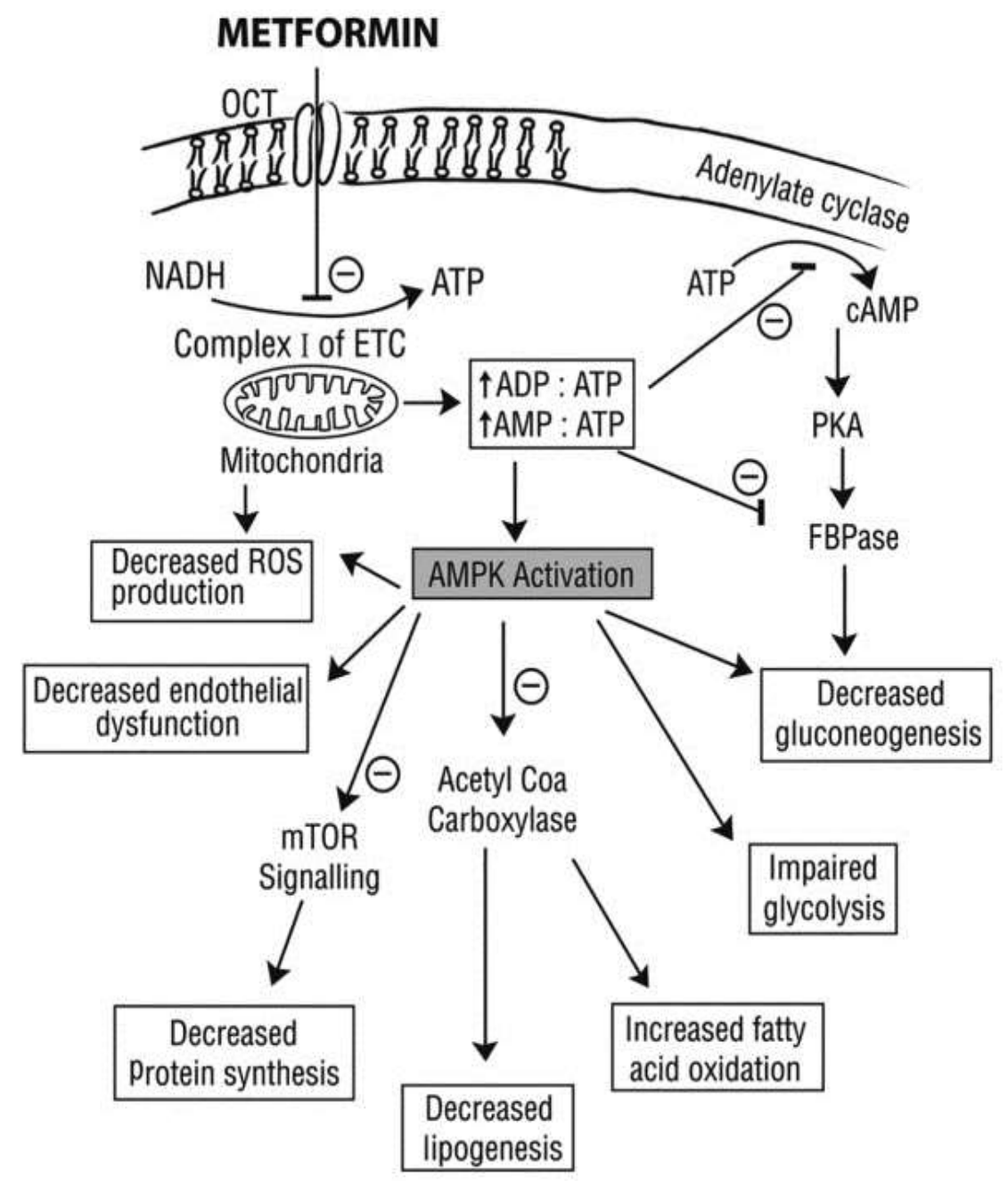

Figure 2. Mechanism of action of metformin

Taken from Priya, G., \& Kalra, S. (2018). Metformin in the management of diabetes during pregnancy and lactation. Drugs in context, 7, 212523. https://doi.org/10.7573/dic.212523 
Metformin is incompletely absorbed in the intestinal mucosa, it shows stable concentrations in plasta within the first 24 and 48 hours after its ingestion, its use is contraindicated in patients with renal failure. [9]

\section{Perinatal effects of metformin}

Metformin is well tolerated in most patients, although it does cause gastrointestinal adverse effects such as abdominal discomfort, loose stools, and diarrhea. In general, these side effects appear shortly after the start of metformin treatment and disappear quickly after stopping it. Metformin is not associated with hypoglycemia or weight gain and reduces the risk of complications and mortality

As far as we are concerned, the use of metformin in patients with the diagnosis of GD is considered a safe management since no serious complications have been reported with its use, neither maternal, nor fetal, nor newborn, with a rate high efficiency of $53.7 \%$ when it was used as the only drug. The amount of insulin required for metabolic control (in patients where it was required) is less than when using insulin alone, and the mother is less likely to suffer from hypoglycemia. Maternal weight gain is lower with the use of metformin compared to those using insulin alone or glyburide for the management of gestational diabetes. [10]

No studies were found where differences will be observed between patients and their children when they used metformin. Long-term followup of newborns is important to assess in the future to verify that everything is going well in the motor and social development of the children. [11]

Published studies on the perinatal effects of metformin in women with gestational diabetes show that metformin improves glucose tolerance and reduces the accumulation of body weight and fat mass in the offspring in adulthood. A comparative study (metformin vs placebo) ( $\mathrm{n}=849$ patients) reported that obstetrically metformin was associated with a lower maternal weight gain ( $p$ 0.0002), the literature refers unsatisfactory results in the investigation of lifestyle changes and diet to reduce the weight gain in pregnant women with obesity, however in this study, the change in lifestyle and adherence to pharmacological treatment was positively evidenced by the weight gain found in the women included in this study and it is reported at an estimated $7.9 \mathrm{~kg}$ during gestation. [12]

The data collected during their research in the study carried out by DR Álvaro Joffre luna et al, demonstrate that pharmacological management with metformin and the advantage of lower weight gain during pregnancy shows a lower incidence of low weight for age In addition to exposing the advantages of the consumption of this drug with respect to the increase in maternal weight and the weight of the newborn, as we well know the risk of suffering from hypertensive diseases during pregnancy due to gestational diabetes is due to fluctuations in the levels of glucose, which generates a greater part in endothelial function, compared to sustained hyperglycemia, for which comparative analyzes have been carried out in which a slight increase in the incidence of hypertensive diseases of pregnancy was reported in the group that were managed with metformin compared to other drugs such as insulin without statistically significant differences. [13]

It should be noted that there is evidence showing that metformin reduces the risk of hypertensive diseases of pregnancy and is associated with a lower percentage of pre-eclampsia. [13.1]

Different studies have shown that the majority (93.8\%) of pregnant women achieve glycemic control using metformin therapy, with a low rate of failures and side effects $(4.6 \%)$ [13,2]

The MIGTOFU, whose objective the study gestational diabetes treated with insulin vs metformin, demonstrated lower rates of severe hypoglycemia $(3.3 \%$ vs $8.1, \mathrm{p}=0.008)$ in those treated with metformin and maternal glycemia during pregnancy was similar in the two subgroups. [14]

Thanks to all the research found, it can be concluded that there is a good relationship between the use of metformin and obstetric and perinatal findings in high-risk pregnant patients with gestational diabetes, because it is low-cost and is available to all in any stratum and that the route of administration contributes to adherence to treatment by patients. (fifteen)

A strength of the current study is the methodology implemented, with respect to the literature search, and steps in the selection of relevant articles, quality assessment and data extraction. However, this study has several limitations, which should be taken into account before reaching a conclusion, within these are the little evidence from clinical studies that show that metformin generates any adverse effect on pregnancy or the fetus.

\section{Conclusion}

It can be emphasized that during the research carried out it was concluded taking into account the collection of data from various sources, where it has been shown that the use of metformin in pregnant women diagnosed with gestational diabetes, treated with this drug, does not exist to date or The causes and / or adverse effects that complicate or endanger both the fetus and the mother are unknown, as well as complications during the gestation period, since according to the results obtained in the research, a high percentage was found, around a $70 \%$, where the patients report efficacy of the drug and a small percentage of side effects, the fetuses were also followed during the gestation period, they did not present any anatomical or cognitive abnormality after delivery, but it is suggested to follow up to babies exposed to metformin later on.

\section{References}

1. Artavia, A. L. E., \& Vaglio, R. E. F. (2019). Lo nuevo en diagnóstico y tratamiento de diabetes mellitus gestacional. Revista Medica Sinergia, 4(4), 41-54.

2. Serna-López, L. V. (2020). Manejo nutricional de las madres con diabetes gestacional, revisión bibliográfica (Bachelor's thesis, Ciencias de la salud).

3. Torres, W. P. R., Juez, A. E. M., González, J. L. G., Barzola, C. V. R., Vélez, D. G. S., Torres, D. A. R., ... \& Nájera, R. D. M. (2018). Diabetes gestacional: fisiopatología, diagnóstico, tratamiento y nuevas perspectivas. Archivos Venezolanos de Farmacología y Terapéutica, 37(3), 218-226.

4. Sanchez Ortiz, B. M. (2017). Diabetes gestacional: actualidades y desafíos en el diagnóstico, manejo y sus complicaciones obstétricas.

5. Ovares Quirós, D., \& Sánchez Guzmán, A. V. (2021). Incidencia de recién nacido grande para edad gestacional o producto macrosómico en mujeres diagnosticadas con diabetes mellitus gestacional A2 tratadas con glibenclamida o metformina, como monoterapia o tratamiento combinado, comparado con insulina en el Servicio de Obstetricia del Hospital de la Mujer Dr. Adolfo Carit Eva entre enero 2015 y diciembre 2018: estudio de cohorte retrospectivo y longitudinal.

6. López-Reyes, A. E., Escobedo-Aguirre, F., Lugo-Cruz, M. P., Jaén-Vento, L. A., \& Macías-Amezcua, M. D. (2021). Efectos perinatales de la metformina en diabetes gestacional. Clínica e Investigación en Ginecología y Obstetricia, 48(3), 100636.

7. Baron Villela, C. A. (2019). Uso de metformina y su efecto hipoglicemiante en diabetes gestacional Hospital Nacional Luis Nicasio Saenz 2017-2018.

8. Guevara Pérez, F. C. (2021). Resultados perinatales con el uso de metformina en Diabetes mellitus gestacional del servicio de Gineco-obstetricia del Hospital Bautista. Enero 2019-diciembre 
2020 (Doctoral dissertation, Universidad Nacional Autónoma de Nicaragua, Managua).

9. Guzmán González, J. D. (2020). Resultados perinatales de pacientes con diabetes gestacional de acuerdo con su tratamiento.

10. Del Pino Martínez, R. F., \& Tapia Cobos, A. G. (2019). Complicaciones perinatales de pacientes con diabetes gestacional vs diabetes pregestacional del Hospital IESS Ceibos y Hospital Teodoro Maldonado Carbo en el periodo enero 2018-enero 2019.

11. Vera González, J. R. D. J. INCIDENCIA DE DIABETES MELLITUS TIPO 2 COMO RESULTADO DE LA RECLASIFICACIÓN DE DIABETES GESTACIONAL EN EL HOSPITAL MATERNO INFANTIL DEL ISSEMYM, DURANTE EL PERIODO 01 DE ENERO A 31 DE DICIEMBRE DEL 2019.
12. Bougherara, L., Hanssens, S., Subtil, D., Vambergue, A., \& Deruelle, P. (2018). Diabetes gestacional. EMC-GinecologíaObstetricia, 54(1), 1-11.

13. Joffre Luna, Á. (2020). Resultados obstétricos y perinatales del uso de metformina en pacientes con diabetes gestacional en el Hospital General Zona Norte de Puebla.

14. CELESTINO SANABRIA, C. I. N. D. Y. DIABETES GESTACIONAL, COMPOSICIÓN CORPORAL Y ANTECEDENTES HEREDO-FAMILIARES EN PACIENTES DEL HOSPITAL MATERNO PERINATAL "MÓNICA PRETELINI SÁENZ.

15. Miranda, P. J. P., Palacios, L. P. T., Cueva, J. L. C., Avilés, G. A. H., Maldonado, E. I. B., Moya, J. I. E., ... \& Lozada, E. M. V. (2019). Rol de la metformina en el tratamiento de la diabetes mellitus gestacional: situación actual. Archivos Venezolanos de Farmacología y Terapéutica, 38(2), 234-239.
This work is licensed under Creative Commons Attribution 4.0 License

To Submit Your Article Click Here: $\quad$ Submit Manuscript

DOI: $10.31579 / 2642-9756 / 094$
Ready to submit your research? Choose Auctores and benefit from:

$>$ fast, convenient online submission

$>$ rigorous peer review by experienced research in your field

$>$ rapid publication on acceptance

$>$ authors retain copyrights

$>$ unique DOI for all articles

$>$ immediate, unrestricted online access

At Auctores, research is always in progress.

Learn more https://auctoresonline.org/journals/women-health-care-and-issues 